\title{
Phosphorus Urine Excretion Rate
}

National Cancer Institute

\section{Source}

National Cancer Institute. Phosphorus Urine Excretion Rate. NCI Thesaurus. Code C117845.

A determination of the amount of phosphorus being excreted in urine over a defined period of time. 